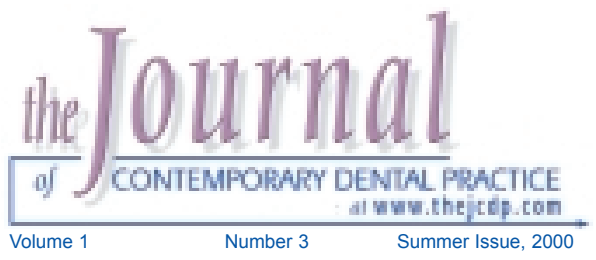

\title{
Internet Resources for Dentistry: Computer, Internet, Reference, and Sites for Enhancing Personal Productivity of the Dental Professional
}

\section{Gary F. Guest, DDS}

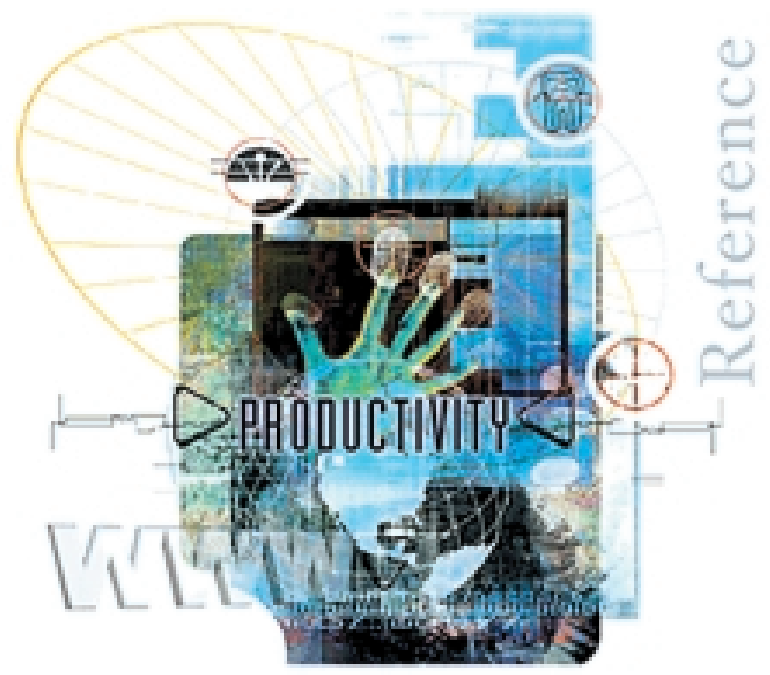

Abstract

At the onset of the new millennium the Internet has become the new standard means of distributing information. In the last two to three years there has been an explosion of e-commerce with hundreds of new web sites being created every minute. For most corporate entities, a web site is as essential as the phone book listing used to be. Twenty years ago technologist directed how computer-based systems were utilized. Now it is the end users of personal computers that have gained expertise and drive the functionality of software applications. The computer, initially invented for mathematical functions, has transitioned from this role to an integrated communications device that provides the portal to the digital world. The Web needs to be used by healthcare professionals, not only for professional activities, but also for instant access to information and services "just when they need it." This will facilitate the longitudinal use of information as society continues to gain better information access skills.

With the demand for current "just in time" information and the standards established by Internet protocols, reference sources of information may be maintained in dynamic fashion. News services have been available through the Internet for several years, but now reference materials such as online journals and digital textbooks have become available and have the potential to change the traditional publishing industry. The pace of change should make us consider Will Rogers' advice, "It isn't good enough to be moving in the right direction. If you are not moving fast enough, you can still get run over!" The intent of this article is to complement previous articles on Internet Resources published in this journal, by presenting information about web sites that present information on computer and Internet technologies, reference materials, news information, and information that lets us improve personal productivity.

Neither the author, nor the Journal endorses any of the sites or products listed, but include these references and links as a matter of convenience for its readers.

Keywords: Internet, world-wide web, dentistry, dental resources, reference resources, news and information, computer and Internet technology 


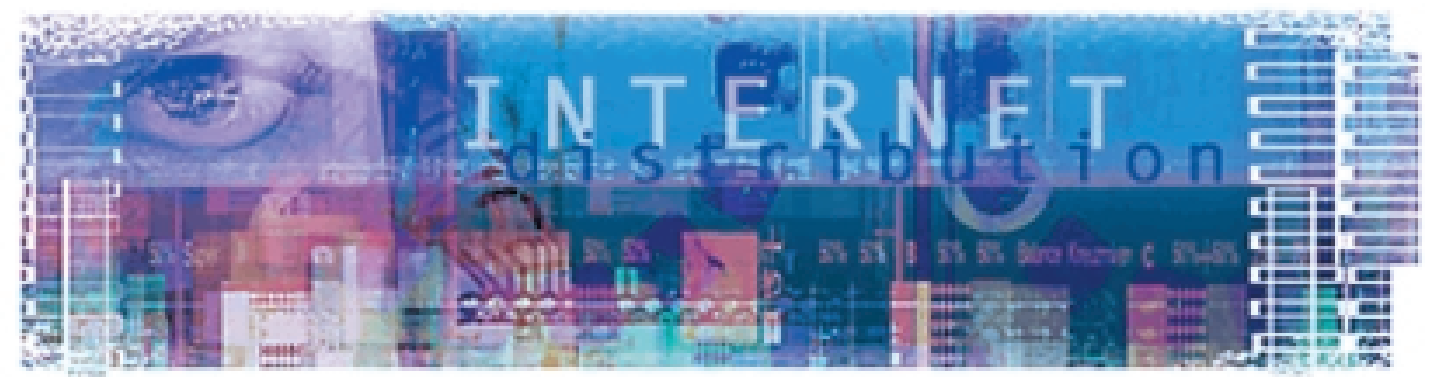

\section{The Computer Industry}

The computer industry, along with the entertainment business, is migrating to "internet-distribution" as a fundamental delivery mechanism. Examples of this migration include the marketing and sales of software applications, the distribution of version updates and user guides, and the marketing and sales of other computer products available for downloading. These capabilities allow the computer industry to provide more costeffective solutions and business practices helping reduce the cost to the consumers in the long run. Wise consumers need to familiarize themselves with the use of the Internet as a delivery media of content and the avenue to "e-commerce."

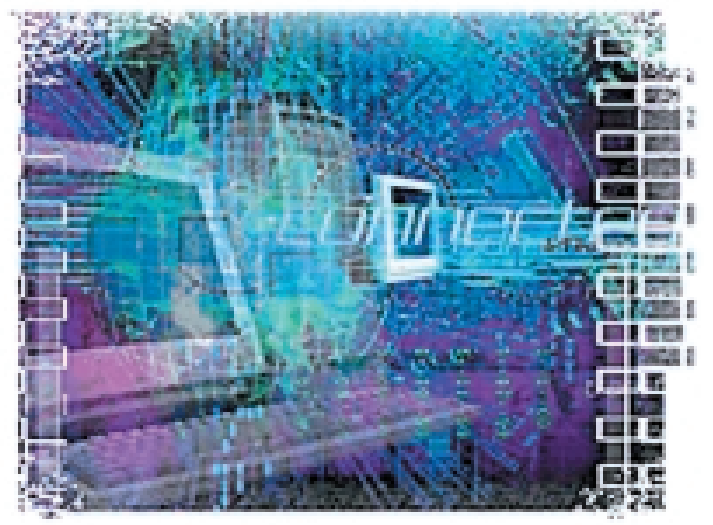

\section{Finding Hardware \\ Apple ${ }^{\circledR}$}

http://www.apple.com/

The site has a very intuitive homepage to access Apple-related resources including news on products and announcements from the company.
Plenty of links to companies producing Mac applications are also found here. Apple now sells directly to the customer via the WWW at the "Apple Store," where consumers can configure units to meet personal specifications including the addition of accessories and peripheral equipment. Customers can also order Apple software and purchase Apple's new iBook online. Customer support can be accessed to review frequently asked questions and obtain "fax back" support.

Apple's Quicktime ${ }^{\circledR}$ technology has become a cross-platform product to deliver both still and video images and is widely supported on the Internet. Visitors can downloaded the Quicktime player as freeware. There are plenty of links to many other sites utilizing Quicktime for posting multimedia content.

\section{Dell Computer http://www.dell.com/}

This company has become a major technology vendor due to web-based e-commerce.

Personalized computer systems can be ordered using an interactive ordering mechanism provided for potential customers. Computer systems can be individually configured, interactively priced, then ordered online by the customer. Dell is considered to be a leader in this innovative sales and support infrastructure, largely due to online sales. This sales and service strategy has been emulated by other technology enterprises and non-computer companies. You can also purchase refurbished computers, order parts, and set up service plans from this site.

\section{Accessing Information: "Critical Thinking Required"}

Readers bewarel Anyone can now be a publisher and it behooves us to think critically about the content presented on the Internet. One must be prepared to judge the quality of information encountered on the World-W/de Web (W/NWW) (refer to previous articies in this series). The individual user of Internet information must also determine the relevance of the posted content to their individual needs before applying it. 


\section{Microwarehouse}

\section{http://www.warehouse.com/}

All three of the Microwarehouse Catalog services (PC, Mac, and Networking) are available from this site, including descriptions of products, pricing, and the ability to purchase them online. This company's site is one of the many good examples of comprehensive e-catalogs for hardware, software, and peripheral devices.

\section{Intel}

http://www.intel.com

Besides being a microprocessor manufacturer and finding information about their line of products, the Intel site also has information about personal web pages and software applications such as Internet Video Phone.

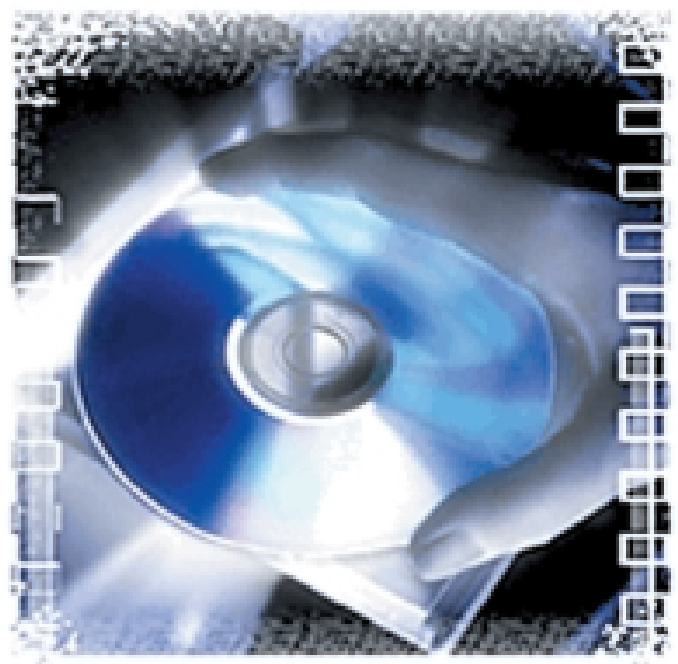

\section{Finding Software}

\section{Adobe}

\section{http://www.adobe.com/}

Adobe is one of the premier companies in computer image processing. The recently innovative homepage for Adobe now has divisions between products they offer for web development, print and publication, motion, and e-paper. Adobe also provides significant content, in a book-like/newsletter format providing users tips and tricks for using their products as well as their innovative uses of best practices utilizing their technologies in the area of print, digital, or web-based resources. You can also download plug-ins and freeware such as Adobe Acrobat Reader ${ }^{\mathrm{TM}}$, which is a cross-platform standard for the distribution of documents in a digital format. Adobe also provides extensive technical information and online articles that supplements user manuals.

\section{Microsoft \\ http://www.microsoft.com/default.asp}

Microsoft's products, which have become the defacto standard for many businesses, provides an extensive site with information about all of their products including entertainment software.

Microsoft's homepage offers access to a variety of sources of information including the products and services they support. This includes support for professional software developers and the general computer user. The site also offers access to other Microsoft resources such as MSN, software patches and freeware ,and provides helpful links to information about upcoming events of interest to visitors.

\section{Macromedia}

http://www.macromedia.com/

With the increase in the use of Flash technology in web site design to display sophisticated graphics, Internet users will need to access the Macromedia site to download their Flash Player plug-in application. The free download area on the web site lets you access Shockwave, Flash, and Authorware players, which are required for sophisticated multimedia playback over the Internet. This technology vendor's forte is the software utilized by many developers to build computer-assisted instruction and tutorials. Trial versions of their software are also available for download.

\section{Red Hat} http://www.redhat.com

If you are thinking about switching to Linux OS, the open standards PC operating system, at your home or office, a visit to this site will be worth your time. Red Hat has developed their own version of Linux which can be ordered online. There are also many links to software written for Linux OS here. 


\section{Tucows}

http://tucows.wau.nl

TUCOWS has been a major Internet software distributor since 1993. It provides comprehensive reviews of software and downloads. With multiple affiliated mirror sites on a worldwide-basis, site visitors have effective links to download all versions of Windows, Mac, Linux, BeOS's Communication, Networking, Multimedia and Internet applications, as well as an assortment of entertainment software. In addition, PDA (Personal Digital Assistant) applications for Palm, WinCE, Epoc/Psion, and Nueton can be downloaded from this site.

\section{Download.com}

http://download.com

Download.com is another mega site for software downloads. Here site visitors can find links to software applications for the PC, Mac, and Linux OS computers including plug-ins, business applications, and entertainment software.

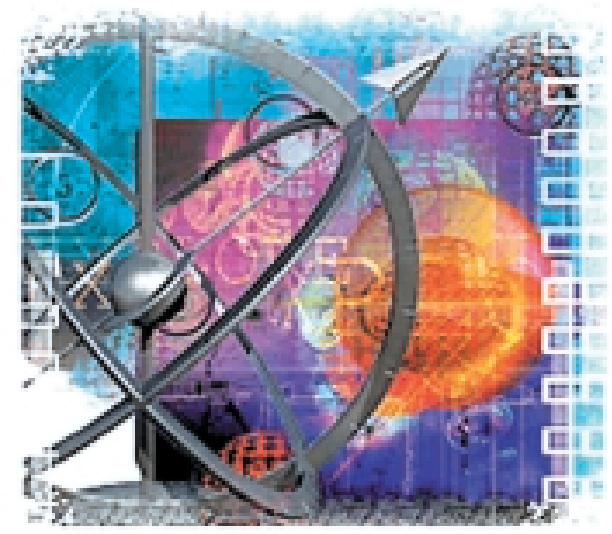

\section{Internet Related Software and Resources}

\section{Netscape Corporation $\AA$}

http://home.netscape.com/

Here, the latest versions of Navigator ${ }^{\mathrm{TM}}$ and Communicator $^{\mathrm{TM}}$ and a variety of plug-ins can be downloaded. Descriptions of other Netscape products are also included at the site. One of the largest growth areas in the computer industry will be in Intranet applications and their management. The Netscape site provides valuable information about how to acquire support services. The site also has interesting articles on Internet topics, such as understanding security when doing online shopping.

\section{Earthlink Network http://www.earthlink.com}

Want to get on board with one of the rising Internet Service Providers (ISP) that has become a major player on the Internet? You will find that Earthlink is one of those. From their site, you can find Internet provider rates for both home and businesses. In addition, information about utilization of the web, how the new high speed connections work, as well as how to build your own web site using Earthlink as the conduit can be found at this site.

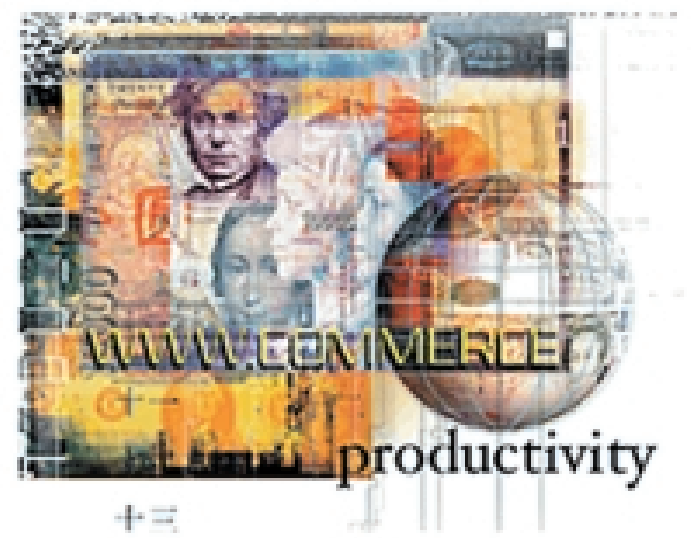

\section{Personal Productivity and the Net}

The Internet can assist us in just about every aspect of our life, and knowing what's out there is half the battle. The benefit to the Internet is getting information when you are ready for it regardless of the time of day, or day of the week. Aside from information related to dentistry, dental professionals should take advantage of the information available on the Internet to help us make more informed choices as a consumer. There is no question that the growth of e-commerce will continue. It is also true that there will be a continued migration from non-searchable paper-based information to highly integrated searchable data on computer-based systems.

\section{Kinkos}

http://www.kinkos.com/

Everybody works up to the last minute, so you will probably have a need to use Kinkos services at some point at home or on the road. Readers can search for the closest location across the country as well as ship computer files over the Internet for paper copies to be produced at one of their locations rather than ship documents by mail. (Use of Adobe ${ }^{\circledR}$ PDF files, or the Kinkos own KDF files is recommended.) 


\section{Consumer World}

http://www.consumerworld.com

When decisions have to be made on buying goods and services, it is helpful to have unbiased comparisons. This site has product reviews and price comparisons, consumer references such as consumer price index, home repair, through links to such sites as Hometime.com, where you can get some ideas about getting started on those projects around the house all the way to detailed "how to" instructions. Links to consumer and travel agencies can also be found at Consumer World's site.

\section{Kiplinger.com}

http://www.kiplinger.com

For information on investments, insurance, and articles related to business management visit this site. Kiplinger is a recognized authority in the business world and plenty of tips for investing can be found here as well as links to their software products.

\section{Edmund's Automotive Buying Guide http://www.Edmund.com}

If you are in the market for a new or used car, Edmund's will be a good starting place. You can find information about car pricing including options and current dealer incentives, ratings, and guidance for making that purchase. If you are selling a car, you can make a window label displaying the car's options and recommended price.

\section{Homes.com}

http://www.homes.com

Are you confronted with moving or thinking about changing schools? This site can provide you with area facts such as demographics, schools, crime statistics, and then lets you compare neighborhoods. Dental professionals may be interested in checking out the neighborhood around their office.

\section{InsideSpaces.com}

\section{http://www.insidespaces.com}

Readers can find more "how to" information for home projects including a quick reference, more detailed information, or a pictorial "dictionary" of terms such as tools and materials used in home repairs. Many of the "how to's" are well illustrated and a few even have downloadable videos.

\section{Travelocity.com}

\section{http://www.travelocity.com/}

This is one of the most comprehensive travel sites on the WWW. However, like many sites one must register as a user. At Travelocity.com one can search for air fares and make online reservations (including seat reservations). The same is true for car, hotel and package vacation reservations. User can also access databases such as travel guides and atlases of maps and photos of hotels and airports of cities of destination.

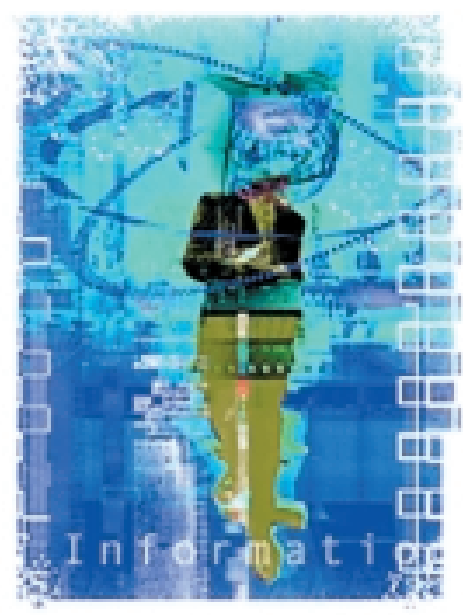

\section{World Wide Web Sites for Reference Information}

\section{Desktop Reference Agent http://www.Il.mit.edu/Deskref}

In addition to providing convenient access to a number of references using "Quick Reference" and "Reference Center," the Almanac portion of this site provides the current official Greenwich time and access to a variety of news resources. An interesting twist to the Almanac component is the link to images provided by the Living Earth Inc. This site also includes links to digital libraries. As a part of MIT, there are several sections restricted to faculty use only.

\section{Dictionary.com http://www.dictionary.com}

Have you ever been preparing a document and need to look up the meaning of a word? Or have you wanted to translate a word into a foreign language? This site enables the reader to search for full definitions of words. There is also a section for translation of words from English to German, French, and Spanish. Another interesting resource this site offers is a medical dictionary that displays medical terms referenced by lay terms. You can also find links to news sites and periodicals here. 


\section{Global Statistics}

http://www.stats.demon.nl

What's the most populated state, the tallest buildings and dams in the world, the largest and most profitable companies in the world? Here you can find the answers to these and many other questions with user friendly access to statistical information. The site presents much of the information in a easy to view chart format and references the sources for the information posted.

\section{The Internet Public Library http://www.ipl.org}

If you are just interested in visiting this library, be prepared to stay awhile. This site will help you find other useful sites using a system similar to that used by someone actually going to a library to find a resource. In fact, you get a graphical representation of content areas including references, education, art, humanities, law, government, business, economics, social sciences, computers, and the Internet. This site's strength is its broad range of subject areas linking to other sites. In addition, its access to library exhibits gives the visitor the sense of a virtual library experience.

\section{The World Factbook 1999}

\section{http://www.odci.gov/cia/publications/factbook/i} ndex.html

This site would be of interest to the serious travel$\mathrm{er}$, or to someone interested in world events. It provides background information on all countries in the world. Information about geography, world populations, communications and transportation in each country, as well as transnational issues is available. This site provides the public with information derived from intelligence at the Central Intelligence Agency (CIA).

\section{WannaLearn.com}

http://www.wannalearn.com

This site attempts to take information gathering a step further by providing an online mechanism for obtaining a range of information about topics from a basic level to a more advanced level. It even provides an opportunity to develop the skills of more sophisticated users. Topics include everything from academic subjects such as English or Math, computers and the Internet, and financial management such as investing and buying a house. This site utilizes the concept of time, space, and independent learning by providing a multitude of skill level courses. It also provides information with links to material from other authors that meet the site's criteria for web-based learning.

\section{How Stuff Works} http://www.howstuffworks.com

In addition to understanding how computers and the Internet work, this site offers information on a wide range of topics, all the way from "how the engine in your car works" to "how a toaster works." This site provides introductory level information. Other interesting topics include such areas as "how your coffee maker works," "how jet engines and cruise missiles work," as well as a number of references on telecommunication and electronics. Dental professionals might want to check out the section on "how dental school works."

\section{The Gallup Organization http://www.gallup.com}

This organization maintains a web presence for linking to their news services and prior surveys they have conducted. You can obtain the latest public opinion on topics ranging from politics and foreign policy to the use of the Internet. The Gallop Organization posts the results of their surveys online. In addition to the news-like format on the homepage this web site also includes the "Gallop Path," which facilitates strategic planning and outcome assessment for running businesses. Dental healthcare professionals might find this interesting in developing business plans and outcome assessments for their practice. Even though this information is largely pertinent to stock held companies, many of the philosophical ideas are applicable to the dental practice.

\section{AnyWho}

http://www.anywho.com

If you are trying to find phone numbers of old friends or need access to phone books in other cities, this site has a nice search engine to find those quickly. Like many phone number sites, it is separated into white pages and yellow pages, but also links to the "800" number directory. 


\section{News Sites}

\section{CNN Interactive}

http://www.cnn.com

This is a premier site for keeping up with what's going on in the rest of the world. Many newspaper and television stations have web sites providing news, weather, and sports updates. Check to see if your local paper or television station has a site. Available at the CNN Interactive site is international, national and local news, political information, and general topics of information ranging from weather and sports to arts and lifestyles. Additional links to multimedia resources and archives, e-mail services, and chat rooms are available. The site also allows visitors to customize their own CNN homepage configuration.

\section{USA Today}

http://www.usatoday.com/

Much like other news sites, this online version of popular print product is a "news and information," site that also contains links to many other nonnews related resources such as classified ads and online shopping. As you might expect, the USA Today standard categories of information and links include sections such as Nationline, Washington, World for News Information, Stocks for Business News, and the Sports section. Also included are sections for Technology, Books, Careers, Travel, and Health.

\section{Weather.com}

\section{http://www.weather.com}

Weather, unpredictable as it is, can even be more frustrating when traveling. Through this site one can access all regional and local weather conditions such as forecasts and maps for current weather conditions. Links to access local forecast have become a standard for sites posting national weather information. Once you select your destination for that next trip, check out the weather forecast on this site to avoid guessing whether or not you should pack that umbrella.

\section{Conclusion}

The Internet has many uses outside of our professional lives. Society has moved into an era of the demand for "just in time help and services." Internet and computer-based technologies not only allows wide distribution of information, but it now provides for information to be much more dynamic and up-to-date. Individually, Internet users will develop their own search and cataloging strategies for their favorite and most useful resources.

Society must be better prepared and organized, if its citizens hope to make more informed choices; if they aspire to be better consumers, they must learn how to utilize the electronic information resources and services available. Many Internet users may have now reached a point of limitation for accessing the rich multimedia content that can be delivered through the Internet. That limitation is "bandwidth," or how much data can be transmitted to the end user. The Computer and Telecommunications Industry have responded with communication devices that allow for more data to be sent to the end users. The introduction of such products such as cable modems, telephone-based DSL services, data compression applications that facilitate information transmission and technologies that allow web users to launch applications on remote computers from their own browser are all attempts at reducing the bandwidth bottleneck. 


\section{References}

1. Apple http://www.apple.com/

2. Dell Computer http://www.dell.com/

3. Microwarehouse http://www.warehouse.com/

4. Intel http://www.intel.com

5. Adobe http://www.adobe.com/

6. Microsoft http://www.microsoft.com/default.asp

7. Macromedia http://www.macromedia.com

8. Red Hat http://www.redhat.com

9. TUCOWS http://tucows.wau.nl

10. Download.com http://download.com

11. Netscape Corporation http://home.netscape.com/

12. Earthlink Network http://www.earthlink.com

13. Kinkos http://www.kinkos.com/

14. Consumer World http://www.consumerworld.com

15. Hometime.com http://www.hometime.com

16. Kiplinger.com http://www.kiplinger.com

17. Edmund's Automotive Buying Guide http://www.Edmund.com

18. Homes.com http://www.homes.com

19. InsideSpaces.com http://www.insidespaces.com

20. Travelocity.com http://www.travelocity.com/

21. Desktop Reference Agent http://www.Il.mit.edu/Deskref

22. Dictionary.com http://www.dictionary.com

23. Global Statistics http://www.stats.demon.nl

24. The Internet Public Library http://www.ipl.org

25. The World Factbook 1999 http://www.odci.gov/cia/publications/factbook/index.html

26. WannaLearn.com http://www.wannalearn.com

27. How Stuff Works http://www.howstuffworks.com

28. The Gallup Organization http://www.gallup.com

29. AnyWho http://www.anywho.com

30. CNN Interactive http://www.cnn.com

31. USA Today http://www.usatoday.com/

32. Weather.com http://www.weather.com

\section{About the Author}

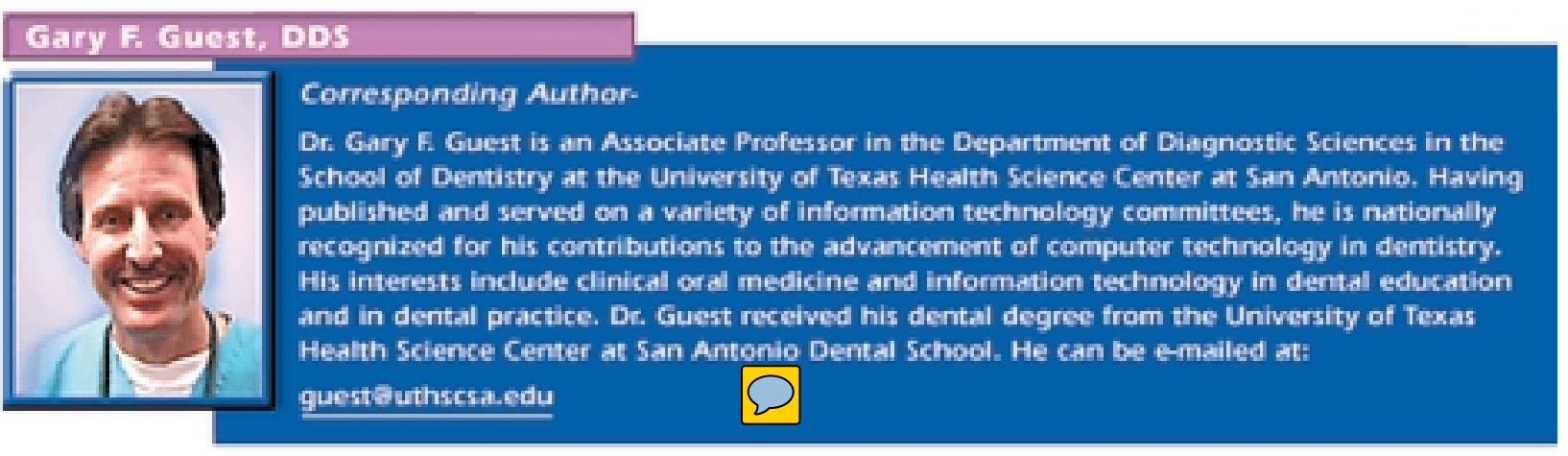

